\title{
Effects of Different Simulated Management Intensities on The Genetic Diversity of a Heart-of-palm Tree Natural Population (Euterpe edulis Martius)
}

\author{
By Juliano Zago dA Silva ${ }^{1), 2)}$ and Maurício Sedrez dos Reis ${ }^{1), 3)}$
}

(Received $18^{\text {th }}$ February 2009)

\begin{abstract}
The objective of this study was to evaluate the impact of selective logging on genetic diversity and inbreeding a heart-of-palm tree (Euterpe edulis), simulating different cutting intensities. To detect the effects of logging, we first performed the genetic characterization of the reproductive plants present in 24 plots that were allocated in Ibirama-SC, Brazil. For the genetic characterization we used allozyme markers, and for simulating the occurrence of different cutting intensities $(5,10,20,30,40$, 50, 60 and 150 seed-trees/ha) we performed 1000 resamplings within the total seed-tree group (599). Thus, it was possible to compare the genetic diversity among the different cutting intensities and the unmanaged population, through alterations to the allelic frequencies, heterozygosity, loss of alleles and increase in the inbreeding. The results of genetic indexes for different cutting intensity were variable, but all presented the same tendency towards genetic diversity reduction when the density of the seed-trees/ha was reduced. The results show that the density of 60 seed-trees/ha, or higher are the most indicated when the objective is to utilize this natural resource in a sustainable way as regards the management issues, because they did not present loss of alleles or reduction in the number of polymorphic loci, and also because they presented the lowest reductions in the observed and expected heterozygosity index and fixation index.
\end{abstract}

Key words: Euterpe edulis, natural population management, effective population size, genetic diversity, heart-of-palm, allozyme markers.

\section{Introduction}

The Euterpe edulis heart-of-palm tree is a species from the Arecaceae family, a native family of the Brazilian Atlantic Forest, and it is economically valuable because it is the main heart-of-palm producer in this region, which made it an intense exploitation target from the 1960s onwards (FANTINI et al., 2000). This species originally presented vast and expressive distribution in almost the entire Atlantic coast pluvial forest zone, even up to an altitude of 600 or $700 \mathrm{~m}$, especially when closer to the coast.

A knowledge of heart-of-palm tree natural regeneration dynamics, especially the understanding of factors that predispose the plants to recruiting (here defined as

\footnotetext{
1) From the Departamento de Fitotecnia, Núcleo de Pesquisas em Florestas Tropicais, Universidade Federal de Santa Catarina, Caixa Posta 476, 88034-000 Florianópolis, Santa Catarina, Brazil.

2) E-Mail: jzagos@yahoo.com.br

3) E-Mail:
}

the passage to a subsequent higher class) or elimination (mortality), is very important in a management system because it implicates on the practices to be used and also on the economics of exploitation. This knowledge allows a prediction of the impact caused by intervention in the forest, especially in terms of what refers to the possibility of supply replacement. This replacement depends on the quantity of seed-trees, responsible for the seedling bank maintenance, and also on the plant recruitment process to the superior categories (CONTE et al., 2003).

REIS et al. (1998; 2000a) and CoNTE et al. (2003) verified an increase in the heterozygosity in the passage from the seedling phase to the adult classes. This behavior is related to the high mortality rate found in first categories. These authors suggested that the species recruitment process is related to genetic aspects, such as heterozygote selection, which highlights the importance of the definition of a minimum seed-tree group, capable of supplying the needs of genetic diversity for the continual recruitment of natural regeneration and species evolution. Thus, the ecological sustainability of exploitation depends on how the populations remain after the logging, because these populations will allow re-arrangement of the original supply or the maintenance of reminiscent population genetics and demographic diversity (REIS et al., 2000b).

REIS et al. (2000a), from their studies about genetic diversity distribution and dynamics in heart-of-palm tree natural populations, recommend the maintenance of approximately 60 seed-trees/ha for natural populations under management, with the objective of maintaining the genetic structure and demographic dynamism of E. edulis species. On the other hand, regulations for the management of natural populations in several Brazilian states establish the maintenance of at least 50 seed-trees per hectare. Further, the Paraná State IBAMA/SEMA Resolution $\mathrm{n}^{\circ} 1$ of 2005 establishes the permanence of $40 \%$ of the reproductive individuals in the area, considering a minimum of 50 seedtrees/ha.This study therefore aims to evaluate the impact of different number of seed-trees maintained per hectare in heart-of-palm tree populations under management on the levels of genetic diversity and inbreeding.

\section{Material and Methods}

\section{Study site}

This study was carried out in Ibirama National Forest (SC), situated between $27^{\circ} 00^{\prime}$ and $27^{\circ} 05^{\prime}$ south parallels 
and $49^{\circ} 25^{\prime}$ and $49^{\circ} 30^{\prime}$ west meridians, at an average altitude of $325 \mathrm{~m}$ and $205 \mathrm{~km}$ distant from Florianópolis (SC). The local vegetation is composed of Tropical Atlantic Rain Forest (KLEIN et al., 1986) which suffered exploitation in the $1950 \mathrm{~s}$. Nowadays, it is found in an advanced secondary state of forestall succession.

\section{Sampling design}

The studied area has 38 hectare and 25 permanent plots, measuring $40 \times 40 \mathrm{~m}$, randomly established in 1997. All plots were re-evaluated in 2004, and with this all the seed-trees plants were identified. The total sampled consisted of 599 individuals, and two leaflets were collected from each plant. The genotypes of seed-trees were determined using allozyme markers, revealed from the horizontal electrophoresis, according to KEPHART (1990) and AlfEnAS (1998) and using the protocol suggested by CONTE et al. (2003). Ten allozyme loci were used, resulting in 13 loci $(\alpha$-EST1, $\alpha$-EST2, DIA1, DIA2, PGI, PGM, G6PDH, IDH, NADHDH, PRX1, PRX2, $\mathrm{SKDH}$ and 6PGDH). Details of allozyme analyses can be found in REIS et al. (2000a) and CONTE et al. (2003).

\section{Data analysis}

To detect the effects of forest logging on genetic diversity, the genetic characterization of all reproductive plants (599) found on the plots was done first. Eight sceneries of different numbers of seed-trees remaining after logging were simulated $(5,10,20,30,40,50,60$, and 150 seed-trees per hectare). Then, 1000 re-samplings were performed for each simulated cutting intensity of $5,10,20,30,40,50,60$, and 150 seed-trees per hectare (respectively for a sampling of 19, 38, 76, 114, 152, 190, 228 and 570 plants, among the 599 sampled genetic characterization for $1 / \mathrm{ha}$ ). The management intensities were defined on the basis of the different regulations and recommendations for the species management, mentioned in the introduction.

From the results of 1000 re-samplings, we calculated the average behavior of each cut intensity, the confidence interval and the standard deviation (SD) of these values. This approach aimed to detect and compare the genetic diversity among these intensities and not the managed population, analyzing the effects of variation in population size through alterations in allelic frequency, heterozygosity, loss of alleles and increase in inbreeding.

The genetic diversity was characterized by allelic frequencies and diversity indexes as observed heterozygosity, expected heterozygosity, percentage of polymorphic loci, average number of alleles per locus and fixation index for the total group of seed-tree samples (599) and for the simulated logging intensities. For simulated logging intensities, we also estimated the risk of allele loss (RPA), as well as the risk of diversity reduction (RRD), average diversity reduction (RMD), maximum diversity reduction (RMXD), maximum and minimum values, and SD and confidence interval, for each of the studied diversity indexes. The allelic frequencies and diversity indexes were calculated using program BIOSYS-2 (SwOFFord and SELANDER, 1989).
For the average number of alleles per locus $(A)$ and percentage of polymorphic locus $(P)$, the risk of genetic diversity reduction indexes $\left(R R D_{A}\right.$ and $\left.R R D_{P}\right)$ were obtained through the re-sampling percentage in each management intensity, whose values were below the population average, in the following manner:

$$
\begin{aligned}
& R R D_{A}=\left(100 N R_{A}\right) / 1000=N R_{A} / 10, \\
& R R D_{P}=\left(100 N R_{P}\right) / 1000=N R_{P} / 10,
\end{aligned}
$$

where, $N R_{A}=R e$-sampling number in 1000 , where the average number of alleles per locus was lower than the population average for the referred index $(A)$, for each management density (Figure 1a).

$N R_{P}=$ Re-sampling number in 1000 , where the number of polymorphic loci was lower than the population average for the referred index $(P)$, for each management density (Figure 1a).

The values that refer to the risk of genetic diversity reduction for the observed $\left(R R D_{H_{O}}\right)$ and expected $\left(R R D_{H_{e}}\right)$ heterozygosity also refer to the re-sampling percentage in each management intensity, located below the average, minus the SD presented in each index at 150 seed trees/ha density:

$$
\begin{aligned}
& R R D_{H_{o}}=\left(100 N R_{H_{o}}\right) / 1000=N R_{H_{o}} / 10, \\
& R R D_{H_{e}}=\left(100 N R_{H_{e}}\right) / 1000=N R_{H_{e}} / 10,
\end{aligned}
$$

where, $N R_{H_{O}}=$ Re-sampling number in 1000, that presented $H_{o}$ values lower than the (average of population, minus the SD estimated by 150 seed-trees/ha density) for each management intensity (Figure 1b).

$N R_{H_{e}}=$ Re-sampling number in 1000 , that presented $H_{e}$ values lower than the (average of population, minus the SD estimated by 150 seed-trees/ha density) for each management intensity (Figure $1 b$ ).

For the fixation index, the values referring to the diversity reduction risk $\left(R R D_{f}\right)$ refer to the percentage of re-sampling at each management intensity that are located above the population average, plus the deviation presented by the index on 150 seed-trees/ha density:

$$
R R D_{f}=\left(100 N R_{f}\right) / 1000=N R_{f} / 10,
$$

where, $N R_{f}=$ Re-sampling number in 1000 , that presented higher $f$ values than the (population average plus the SD estimated by 150 seed-trees/ha density) for each management density (Figure 1c).

The variation of allelic frequency in each locus, at 150 seed-trees/ha density, was considered as a natural population, due to the fact that this density included practically all the plants that represented the population. Thus, the values that refer to the risk of genetic diversity reduction per locus also refer to the percentage of resamples in 1000, which presented allelic frequency variation, above and below the population average, subtracting or adding the average of the natural variation of each locus for each management density, depending on the case:

$$
R R D_{\text {locus }}=\left(100 N R_{\text {locus }}\right) / 1000=N R_{\text {locus }} / 10,
$$

where $N R_{\text {locus }}=$ Re-sampling numbers, with allelic frequency variation, above and below the population 


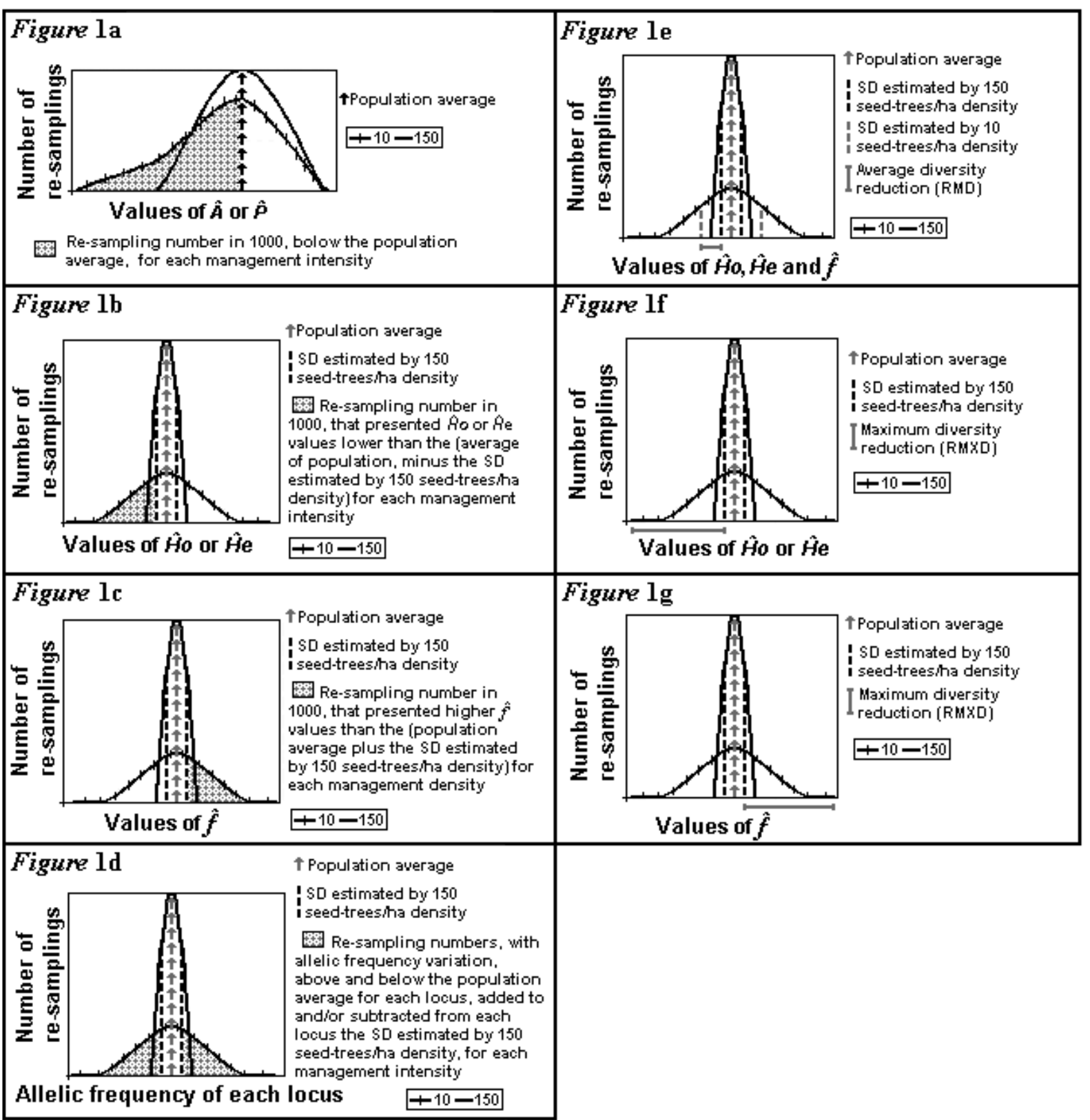

Figure 1. - Models used for the estimate of re-sampling numbers in relation to each simulated management density, for the different diversity indexes that were studied.

average for each locus, added to and/or subtracted from each locus natural SD for each management intensity (Figure 1d).

To obtain the average and maximum diversity reduction estimates for the observed and expected heterozygosity and fixation index, the SD presented by the 150 seed-trees/ha density was also considered as natural, so therefore this was discounted from the population average. Thus, the estimate of average diversity reduction for these three indexes refers to the SD of each management intensity minus the natural SD of the population.

$\mathbf{R M D}_{\mathrm{Ho}, \mathrm{He} \text { and } f}=\mathrm{SD}$ of each management intensity minus the $\mathrm{SD}$ of the population (Figure 1e).

To obtain the maximum diversity reduction for observed and expected heterozygosities, it was necessary to calculate the population average minus the SD presented by 150 seed-trees/ha density, minus the minimum value in each management intensity.

$\mathbf{R M X D}_{\mathrm{Ho} \text { and } \boldsymbol{H e}}=$ Population average minus the population SD minus the minimum value in each management intensity (Figure 1f).

For the fixation index, the calculation of maximum diversity reduction is obtained by subtracting the population average and SD of 150 seed-trees/ha density from the maximum value for each management intensity.

$\mathbf{R M X D}_{f}=$ Maximum value of each management intensity minus the population average SD of 150 seed trees/ha density (Figure 1g).

The values that express the risk of loss of alleles were obtained through the percentage of re-samples in 1000 that presented allelic loss in each locus, for each management density. 
RPA $=(($ Number of re-samples per locus that presented allelic loss at each management density)*100)/1000.

Considering that in natural populations of the species there are a low level of relationship between the individuals, the effective population size $\left(N_{e}\right)$ was estimated according to VENCOVSKY (1997) by the expression: $\hat{N}_{e}=n /(1+\hat{f})$, where $n$ is the sample size and $f$ is Wright's fixation index. The genetic representation was estimated through the relation $\hat{N}_{e} / n$.

\section{Results and Discussion}

\section{Genetic diversity and fixation index in the studied population}

The genetic diversity indexes estimated from the 13 analyzed loci over 599 heart-of-palm seed-trees (158/ha) of Ibirama's natural population (Table 1), revealed the presence of average 2.1 alleles per locus $(\hat{A}), 69.23 \%$ of polymorphic loci $(\hat{P})$ and a genetic diversity of $0.216\left(\hat{H}_{e}\right)$. The average observed heterozygosity $\left(\hat{H}_{o}\right)$ was 0.195 and it was not statistically different from the genetic diversi- ty (t-test). A significant different from zero and positive average fixation index (0.099) was obtained, suggesting inbreeding and that the population was not in HardyWeinberg proportions. These indexes were higher than detected in other tropical species. For example, HAMrICK et al. (1992) estimated a $\hat{H}_{e}$ and $P$ over 38 tropical species of 0.191 and $57.9 \%$, respectively. However, the estimated values of genetic diversity indexes in the studied population were similar to detected in other studies with the species (CONTE et al., 2003; 2008; REIS et al., 2000a).

\section{Genetic diversity and fixation index in the simulated sceneries}

No significant differences were observed between different logging intensities for $H_{o}, H_{e}$ and $f$ (Table 2). It was expected that the average of the different genetic indexes would not present significant differences in the simulations, because the population average for each index is the intermediary point of each data set. Thus, if the random choice of each plant group occurs, there is

Table 1. - Average genetic diversity and fixation index of 13 allozyme loci analyzed for a natural population of Euterpe edulis in Ibirama - SC FLONA. ( $\mathrm{n}=$ average sample size; $\mathrm{A}=$ average number of alleles per locus; $\mathrm{P}=$ percentage of polymorphic loci; $H_{O}=$ observed heterozygosity; $H_{e}=$ genetic diversity; $f$ = fixation index.).

\begin{tabular}{lcccccc}
\hline & $n$ & $\hat{A}$ & $\hat{P}^{1}$ & $\hat{H}_{o}$ & $\hat{H}_{*}$ & $\hat{f}$ \\
\hline All Loci & $597.2(0.4)^{2}$ & $2.1(0.3)$ & 69.23 & $0.195(0.069)$ & $0.216(0.070)$ & $0.099^{*}$ \\
Polymorphic loci $(9)$ & $597.1(0.5)$ & $2.6(0.3)$ & 100 & $0.281(0.085)$ & $0.313(0.082)$ & $0.102^{*}$ \\
\hline
\end{tabular}

${ }^{1}$ Criteria $\mathrm{p}<0.99 .{ }^{2}$ standard deviation. * Significant value through $\mathrm{X}^{2}$ test.

Table 2. - Average diversity indexes per management intensity, from the 13 allozyme loci, analyzed for a natural population of Euterpe edulis, in Ibirama - SC FLONA.

\begin{tabular}{|c|c|c|c|c|c|}
\hline $\begin{array}{l}\mathrm{N}^{\circ} \text { of Seed } \\
\text { Trees/ha }\end{array}$ & $\begin{array}{c}\text { Average } \mathrm{N}^{\circ} \text { of } \\
\text { alleles } / \text { Locus } \\
(\hat{A})\end{array}$ & $\begin{array}{c}\% \text { of Polymorphic } \\
\text { Loci }^{1} \\
(\hat{P})\end{array}$ & $\begin{array}{c}\text { Observed } \\
\text { Heterozygosity } \\
\left(\hat{H}_{O}\right)\end{array}$ & $\begin{array}{c}\text { Expected } \\
\text { Heterozygosity } \\
\left(\hat{H}_{e}\right)^{2}\end{array}$ & $\begin{array}{c}\text { Fixation Intex } \\
(\hat{f})\end{array}$ \\
\hline 150 & $\begin{array}{c}2.100 \mathbf{a} \\
(2.100-2.100)^{4}\end{array}$ & $\begin{array}{c}69.23 \mathbf{a} \\
(69.23-69.23)\end{array}$ & $\begin{array}{c}0.1948 \mathbf{a} \\
(0.1947-0.1949)\end{array}$ & $\begin{array}{c}0.2164 \mathbf{a} \\
(0.2164-0.2164)\end{array}$ & $\begin{array}{c}0.0998 \mathbf{a}^{k-t} \\
(0.0996-0.1000)\end{array}$ \\
\hline 50 & $\begin{array}{c}2.100 \mathbf{a} \\
(2.100-2.100)\end{array}$ & $\begin{array}{c}69,23 \mathbf{a} \\
(69.23-69.23)\end{array}$ & $\begin{array}{c}0.1949 \mathbf{a} \\
(0.1946-0.1952)\end{array}$ & $\begin{array}{c}0.2164 \mathbf{a} \\
(0.2162-0.2166)\end{array}$ & $\begin{array}{c}0.0990 \mathbf{a} \\
(0.0977-0.1003)\end{array}$ \\
\hline 40 & $\begin{array}{c}2.099 \mathrm{~b} \\
(2.099-2.099)\end{array}$ & $\begin{array}{c}69.23 \mathbf{a} \\
(69.23-69.23)\end{array}$ & $\begin{array}{c}0.1949 \mathbf{a} \\
(0.1945-0.1953)\end{array}$ & $\begin{array}{c}0.2164 \mathbf{a} \\
(0.2161-0.2167)\end{array}$ & $\begin{array}{c}0.0995 \mathbf{a} \\
(0.0980-0.1010)\end{array}$ \\
\hline 30 & $\begin{array}{c}2.098 \mathbf{b} \\
(2.097-2.099)\end{array}$ & $\begin{array}{c}69.20 \mathbf{a} \\
(69.17-69.23)\end{array}$ & $\begin{array}{c}0.1949 a \\
(0.1944-0.1954)\end{array}$ & $\begin{array}{c}0.2163 \mathbf{a} \\
(0.2160-0.2166)\end{array}$ & $\begin{array}{c}0.0990 \mathbf{a} \\
(0.0972-0.1008)\end{array}$ \\
\hline 10 & $\begin{array}{c}2.031 d \\
(2.026-2.036)\end{array}$ & $\begin{array}{c}67.15 c \\
(66.93-67.37)\end{array}$ & $\begin{array}{c}0.1949 a \\
(0.1940-0.1958)\end{array}$ & $\begin{array}{c}0.2162 \mathbf{a} \\
(0.2156-0.2168)\end{array}$ & $\begin{array}{c}0.0981 \mathbf{a} \\
(0.0946-0.1016)\end{array}$ \\
\hline 5 & $\begin{array}{c}1.932 \mathbf{e} \\
(1.926-1.938)\end{array}$ & $\begin{array}{c}63.18 \mathbf{d} \\
(62.85-63.51)\end{array}$ & $\begin{array}{c}0.1947 \mathbf{a} \\
(0.1934-0.1960)\end{array}$ & $\begin{array}{c}0.2156 \mathbf{a} \\
(0.2147-0.2165)\end{array}$ & $\begin{array}{c}0.0960 \mathbf{a} \\
(0.0911-0.1009)\end{array}$ \\
\hline
\end{tabular}

${ }^{1}$ Criteria $\mathrm{p}<1 .{ }^{2}$ NEI's unbiased estimate (1978). ${ }^{3}$ Standard deviation. ${ }^{4}$ Confidence interval, obtained with 1000 re-samples. * Significant value through $\mathrm{X}^{2}$ test. ${ }^{* *}$ The values that are followed by the same letters are not different among themselves through the confidence interval. 
an equal chance for superior and inferior values to be combined, therefore maintaining the same average for each index. On the other hand, the $A$ and $P$ were significantly differed in lower density classes (Table 2). The differentiation of the average for these indexes is probably caused by the increasing reduction in the number of rare alleles when the density of seed-trees is reduced, making the chance of low-frequency allele sampling extremely improbable, which tends to gradually dislocate the population average.

The $P$ depends on the $A$ and both parameters presented very high correlation (0.883). Thus, the absence of rare alleles in the lower density classes produces visible effects on $P$ values. Therefore, the $A$ and $P$ values follow a variable pattern. For example, they reduced when the number of seed-trees/ha was reduced. However, the reduction of $A$ values only occurs when the density becomes inferior to 50 seed-trees/ha, which indicates the occurrence of the effects of forest logging on genetic diversity. For $P$, the reduction of these values only occurs when the density becomes inferior to 30 seedtrees/ha, also indicating the loss of genetic diversity due reduction in size of population.

The stabilization for $A$ and $P$ values, occur in densities greater or equal to 50 and 30 seed-trees/ha, respectively (Table 2). This is explained by the fact that the number of alleles, as well as the number of polymorphic loci is finite. Thus, larger samples have a higher probability of representing the alleles present in these loci.

The values of the $f$ were equal and significant different from zero at all management intensities, indicating the occurrence of approximately $10 \%$ of inbreeding (Table 2). For this index, a low and not significant correlation with population density $(r=0.002)$ was observed.

Despite the fact that the average of the different management intensities does not present differences in the studied genetic indexes for all studied densities, the maximum and minimum values, average deviation and risk of genetic diversity reduction for each density (Table 3) show that the management intensities might exert different consequences on the population. The maximum and minimum values, average deviation and risk of genetic diversity reduction were presented as important indicators of each management density's behavior, because they indicate the risk of genetic diversity be loss in each situation. These results show that the lower the seed-trees/ha density, greater are the risks of genetic diversity reduction, as well as the average deviation and the distances of maximum and minimum values relating to the average.

It is also shown (Table 3 ) that for densities $\geq 60$ seedtrees/ha, the samples that were different from the average population do not occur any more, which indicates that this density, or densities that are higher than 60 seed-trees/ha, do not present a risk of genetic diversity reduction. The management densities of 30, 40 and 50 seed-trees/ha showed the loss of alleles as can be visualized by the SD values (Table 3). Nevertheless, these losses were low, which can also be verified through the risk of their occurrence, being respectively of only six- teen, three and one situation in 1000 . Thus, according to this index, these densities could also be recommended for sustainable management plans. On the other hand, the densities of 5, 10 and 20 seed-trees/ha presented a high risk of allelic loss $(>10 \%)$ as well as a high loss of genetic diversity $(>0.035)$, so therefore they are not recommended. Comparing a natural population to a Tabebuia cassinoides-managed population, SEBBENN et al. (2000) observed that in the managed population where only 20 seed-trees/ha were maintained, some alleles were missing. Thus, the authors suggest the maintenance of 60 seed-trees/ha, at least. The loss of alleles in plant species, due the reduction of effective population size, has also been observed by BILLINGTON (1991), OuBorg et al. (1991), HAMrick (1991), FrANKHAM (1996), LANDE (1999), White et al. (1999) and ANDRÉ et al. (2008).

The variation in the parameter $P$ follows the same pattern as the $A$, i.e., the average deviations, as well as the distance of maximum and minimum values and the risk of genetic diversity reduction increases, when the number of seed-trees/ha is reduced. The effects caused by the alteration in the density of reproductive individuals over $P$ are only perceived up to the density of 30 seed-trees/ha. But for the A (Table 3), the effects of this reduction can be perceived up to the density of 50 seedtrees/ha. Consequently, the alteration caused by the change in the density of reproductive individuals is first perceived in the $A$. This difference in the sensibility of the two indexes is due to the fact that the first effect is on the loss of lower frequency alleles, and the percentage of polymorphic loci does not consider the frequency of all alleles, but instead the presence of a minimum of two alleles per locus.

The values for observed heterozygosity (Table 3 ) follow the same variation pattern as the other presented indexes, i.e. the average deviations, as well as the distance of maximum and minimum values and the risk of genetic diversity reduction increase when the number of seedtrees/ha is reduced. However, it can be observed that even at much high densities, such as 150 seed trees/ha, values occur that are different from the population average. Thus, contrary to what was observed, for the $A$ and $P$, all the studied management densities presented a possibility of losses and risks of genetic diversity reduction, which suggests a greater sensibility of this index in detecting effects caused by the variation in the number of reproductive individuals.

Observing the average genetic diversity reduction for $H_{o}$ (Table 3) for different management intensities, it may be observed that the density 50 and 60 seedtrees/ha were very similar, especially if the risks of genetic diversity reduction are considered, which configure these densities as the most indicated due to the smaller losses and risks. These densities presented a high risk of genetic diversity reduction that is to say that depending on the density (50 or 60 seed-trees/ha), there would exist the possibility that $27 \%$ or $25 \%$ of the situations would present values of observed heterozygosity below the population average. However, the average genetic diversity reduction would be relatively low, 
Table 3. - Variation in the average number of alleles per locus $(A)$, in the percentage of polymorphic loci $(P)\left(\mathrm{p}<1\right.$ criteria), observed heterozygosity $\left(H_{o}\right)$, expected heterozygosity $\left(H_{e}\right)$ and fixation index $(f)$ in simulations of different management intensities with 1000 re-samplings from 13 allozyme loci, analyzed for a Euterpe edulis natural population, in Ibirama - SC FLONA.

\begin{tabular}{|c|c|c|c|c|c|c|c|c|c|}
\hline & \multicolumn{9}{|c|}{ Number of Seed-Trees/ha } \\
\hline & 5 & 10 & 20 & 30 & 40 & 50 & 60 & 150 & 158 \\
\hline & \multicolumn{9}{|c|}{ Average Number of Alleles/Locus } \\
\hline Average & 1.93 & 2.03 & 2.09 & 2.1 & 2.1 & 2.1 & 2.1 & 2.1 & 2.1 \\
\hline Minimum & 1.7 & 1.8 & 1.9 & 2.0 & 2.0 & 2.0 & 2.1 & 2.1 & - \\
\hline Maximum & 2.1 & 2.1 & 2.1 & 2.1 & 2.1 & 2.1 & 2.1 & 2.1 & - \\
\hline Standard deviation & 0.096 & 0.073 & 0.035 & 0.013 & 0.005 & 0.003 & 0 & 0 & - \\
\hline \multirow[t]{2}{*}{$\mathbf{R R D}^{*}(\%)$} & 88.6 & 53.5 & 12.7 & 1.6 & 0.3 & 0.1 & 0 & 0 & 0 \\
\hline & \multicolumn{9}{|c|}{$\%$ of Polymorphic Loci } \\
\hline Average & 63.2 & 67.1 & 69.0 & 69.2 & 69.2 & 69.2 & 69.2 & 69.2 & 69.2 \\
\hline Minimum & 46.1 & 53.8 & 61.5 & 61.5 & 69.2 & 69.2 & 69.2 & 69.2 & - \\
\hline Maximum & 69.2 & 69.2 & 69.2 & 69.2 & 69.2 & 69.2 & 69.2 & 69.2 & - \\
\hline Standard deviation & $5.2 * *$ & 3.6 & 1.4 & 0.5 & 0 & 0 & 0 & 0 & - \\
\hline \multirow[t]{2}{*}{ RRD* $(\%)$} & 64.2 & 26.3 & 3.2 & 0.4 & 0 & 0 & 0 & 0 & 0 \\
\hline & \multicolumn{9}{|c|}{ Observed Heterozygosity } \\
\hline Average & 0.195 & 0.195 & 0.195 & 0.195 & 0.195 & 0.195 & 0.195 & 0.195 & 0.195 \\
\hline Minimum & 0.134 & 0.140 & 0.165 & 0.173 & 0.174 & 0.175 & 0.178 & 0.192 & - \\
\hline Maximum & 0.259 & 0.246 & 0.220 & 0.215 & 0.215 & 0.211 & 0.211 & 0.198 & - \\
\hline Standard deviation & 0.020 & 0.015 & 0.010 & 0.008 & 0.006 & 0.005 & 0.005 & 0.001 & - \\
\hline $\mathbf{R M D}^{1}$ & 0.019 & 0.014 & 0.009 & 0.007 & 0.005 & 0.005 & 0.004 & 0.000 & - \\
\hline RMXD $^{2}$ & 0.060 & 0.054 & 0.029 & 0.021 & 0.020 & 0.019 & 0.016 & 0.002 & - \\
\hline \multirow[t]{2}{*}{$\operatorname{RRD}^{3}(\%)$} & 45.4 & 40.9 & 36.7 & 32.8 & 30.7 & 26.7 & 25.0 & 0 & 0 \\
\hline & \multicolumn{9}{|c|}{ Expected Heterozygosity } \\
\hline Average & 0.216 & 0.216 & 0.216 & 0.216 & 0.216 & 0.216 & 0.216 & 0.216 & 0.216 \\
\hline Minimum & 0.165 & 0.181 & 0.193 & 0.198 & 0.203 & 0.206 & 0.207 & 0.214 & - \\
\hline Maximum & 0.264 & 0.250 & 0.237 & 0.236 & 0.230 & 0.228 & 0.226 & 0.218 & - \\
\hline Standard deviation & 0.015 & 0.010 & 0.007 & 0.005 & 0.004 & 0.004 & 0.003 & 0.001 & - \\
\hline RMD $^{1}$ & 0.014 & 0.009 & 0.006 & 0.004 & 0.004 & 0.003 & 0.003 & 0.000 & - \\
\hline RMXD $^{2}$ & 0.050 & 0.034 & 0.022 & 0.017 & 0.012 & 0.009 & 0.008 & 0.001 & - \\
\hline \multirow[t]{2}{*}{$\operatorname{RRD}^{3}(\%)$} & 45.1 & 39 & 33.7 & 29.3 & 25.3 & 25 & 20.3 & 0 & 0 \\
\hline & \multicolumn{9}{|c|}{ Fixation Index } \\
\hline Average & 0.096 & 0.098 & 0.100 & 0.099 & 0.099 & 0.099 & 0.099 & 0.100 & 0.099 \\
\hline Minimum & -0.156 & -0.085 & 0.000 & 0.023 & 0.028 & 0.033 & 0.028 & 0.088 & - \\
\hline Maximum & 0.373 & 0.282 & 0.214 & 0.174 & 0.164 & 0.162 & 0.156 & 0.111 & - \\
\hline Standard deviation & 0.079 & 0.056 & 0.037 & 0.028 & 0.024 & 0.021 & 0.018 & 0.004 & - \\
\hline RMD ${ }^{1}$ & 0.075 & 0.053 & 0.034 & 0.025 & 0.020 & 0.017 & 0.014 & 0.000 & - \\
\hline RMXD $^{2}$ & 0.271 & 0.180 & 0.112 & 0.072 & 0.062 & 0.059 & 0.053 & 0.009 & \\
\hline $\operatorname{RRD}^{3}(\%)$ & 42.4 & 40.8 & 37.3 & 32.5 & 32.5 & 29.4 & 24.9 & 0 & 0 \\
\hline
\end{tabular}

* $\mathrm{RRD}=$ Risk of diversity reduction, referring to the percentage of samples that are located below the population average, for each management density.

*** Values of the SD, on percentage, because the diversity index is a percentage.

${ }^{1} \mathrm{RMD}=$ Average diversity reduction, referring to the SD of each management density, minus the population natural SD $(0.0009 ; 0.0007$ and 0.0038 , respectively).

${ }^{2}$ RMXD = Maximum diversity reduction, referring to the population average $(0.195 ; 0.216$ e 0.0987 respectively), minus the population natural SD (0.0009; 0.0007 and 0.0038 respectively), minus the minimum value on each management density.

${ }^{3} \mathrm{RRD}=$ Risk of diversity reduction, referring to the percentage of samples that are located below the population average, minus the natural variation presented by the population: $\{\%$ samples $<(0.195-0.0009)\} ;\{\%$ samples $<(0.216-0.0007)\}$ and $\{\%$ samples $>(0.0987+0.0038)\}$.

around $0.0046(2.4 \%)$ and $0.004(2.1 \%)$ (Table 3). Nevertheless, the values that were observed for the maximum genetic diversity reduction for these same densities were high, respectively around 9.8 and $8.3 \%$, and due to the low probability of occurrence - one in 1000 - they should not represent any cause for concern. Thus, it can be realized that even though there is a risk of genetic diversity reduction for the $H_{o}$, the losses that occurred at densities of 50 and 60 seed-trees/ha have lower impact. For the other densities ( 5 to 40 seed-trees/ha) the average genetic diversity reductions were elevated, and if added to the high risk they offer, they compromise the sustainability of the management systems, and are therefore not recommended. 
The option for more conservative (high) densities is due to the fact that the alteration in the number of heterozygotes of a population might lead to a certain loss of the genetic diversity for the future generations, with the increase of fixation index. High heterozygosity values are evidence of high genetic stock, and a reduction in its values is connected to undesirable effects that might result in the population's decline. Besides this, it is not known for sure how much of this heterozygosity can be reduced, which leads to the conclusion that heterozygosity is a critical point and conservative attitudes might be essential when the decisions to be made still do not present a sufficient scientific foundation to enable a safe choice.

The most solid scientific foundation found in the attempt to introduce greater safety into this decision is presented by WRIGHT (1931) who suggests that a population that has an effective population size of 50 individuals would present losses of $1 \%$ per generation in heterozygosity, which would make possible a short term genetic conservation (10 generations). Based on this, the 2.4 and $2.1 \%$ losses that were presented by 50 and 60 seed-trees/ha densities, in the event of management, could reduce this time by 2 generations (underestimated 40 years) according to WRIGHT's logic (1931). The other densities, such as 5 and 40 seed-trees/ha, for example, would present a reduction of 10 and 3 generations respectively. This way, even if analyzing the question according to WRIGHT's (1931) proposition, the 50 and 60 seed-trees/ha densities would be the most indicated. However, follow-up studies are necessary to clarify this question.

The behavior of $H_{e}$ (Table 3) was very similar to observed for $H_{o}$ because the average deviations, as well as the distance of minimum and maximum values and risks of genetic diversity reduction, also increase with the reduction in the number of seed-trees/ha. The average and maximum genetic diversity reduction, as well as the SD values and risk of genetic diversity reduction that were obtained for the $H_{e}$, were lower than those that were obtained for the $H_{o}$, suggesting that the alterations that were caused by the change in the density of reproductive individuals should be first realized for the $H_{o}$. Studying a $T$. cassinoides-managed population, where only 20 seed-trees/ha were maintained, SEBBENN et al. (2000) also observed reductions in the $H_{o}$ and $H_{e}$. However, studying 17 Succisa pratensis populations in relation to the population size and genetic diversity, VERGEER et al. (2003) only observed a positive and significant correlation between the population size and $H_{o}$ : for the $H_{e}$, the correlation was not observed. OUBORG et al. (1991), FRANKHAM (1996) and ANDRÉ et al. (2008) also observed a reduction in the $H_{o}$ when the population size was reduced.

The $f$ values (Table 3 ) also follow the same gradient as the other indexes, but are noteworthy because they present a small reduction in the average deviations when density increases are found even for deviations of 0.0038 $(3.85 \%)$ at 150 seed-trees/ha. The elevated values of the SD that were detected at this density suggest the high sensibility of this index to detect the effects of the reduc- tion in the number of seed-trees. Besides this, they show that the alterations caused by the change in the density of reproductive individuals, as well as the effect of the mating system and subdivision, would be first shown on the fixation index, in comparison to the values of the SD that were presented by the $H_{0}$.

Sixty seed-trees/ha is the most indicated management density by the analysis of the fixation index (lower risks and losses). However, still offers a high risk of genetic diversity reduction of $25 \%$ (Table 3), meaning that $25 \%$ of the management plans achieved by this density have the possibility of presenting inbreeding that are higher than those presented by the population average. Thus, it can be realized that the average genetic diversity reduction, like the maximum reduction, can be elevated, but the maximum reduction values have a low probability of occurring, i.e. only one possibility in 1000, and because of this, they should not be a cause for concern. However, the average genetic diversity reduction has a high probability, which certainly is a reason for concern, because $25 \%$ of the management systems that were applied at a density of 60 seed-trees/ha would present higher fixation indexes than the population average.

Comparing the 60 and 150 seed-trees/ha densities, as for the SD values (Table 3), it can be observed that the number of seed-trees/ha would have to be greatly increased in order to obtain management densities with smaller genetic diversity losses and reduction risks for the inbreeding, and that this would even compromise the viability of the management. Therefore, the reduction in the average genetic diversity presented by 50 and 60 seed-trees/ha can be considered as the cost of management realization. Considering that the fixation index alters the heterozygosity, it can be considered that for 50 and 60 seed-trees/ha densities, this cost might be acceptable because the other studied indexes do not present any significant reduction in the density. The other management densities, from 5 to 40 seed trees/ha, presented elevated risks of increase in the fixation index as well as for the decrease for some of the other indexes and, for this reason they are not recommended.

The variations in allelic frequencies for different management intensities at nine loci that presented polymorphisms (data not presented) showed similar behavior, when the number of seed-trees/ha was reduced and the average deviation values, the risk of loss of alleles $(\mathrm{RPA})$, the risk of genetic diversity reduction ( $R R D)$, and the distance of maximum and minimum values were increased proportionally in relation to the average frequency of the population.

Loss of alleles and fixation of alleles was also observed even when detecting the losses for 5 to 50 seed-trees/ha densities and the fixation for 5 to 30 seed-trees/ha densities. This difference of density between the loss of alleles and the fixation of alleles is due to the fact that the fixation of one allele depends on the loss of the other alleles of the locus, but the loss of alleles only depends on the individual frequency of each allele. Thus, the fixation depends more on the intensity of reduction of the density than the loss of alleles, because in these cases, the effect of the density should extend over a group of alle- 
les, being strong enough to eliminate all the other alleles in the locus. However, the effect of density on the loss of alleles might be restricted to one allele only, not depending on the elimination of the other alleles, and the occurrence of this is much more probable.

The expected behavior for the loss of alleles is the same as that verified for fixation. However, the concern directed towards each particular allele, and the frequency of each allele, determines its permanence or elimination, and the relationship between low frequencies and high risk of allelic loss is explicit. In this way, alleles at higher frequencies are only eliminated at low densities, and alleles at low-frequency are easily eliminated.

Total variation in the loss of alleles for different management intensities is present in Table 4. It may be observed that the greatest allelic losses occur at the lower management densities, and when the density is increased these losses are reduced, until they become void. At 5 seed-trees/ha density, we can see a higher percentage of situations with lost alleles, $88.6 \%$ of 1000 resamplings that represent the value of this density, as well as the greater allelic losses per sample, even five alleles. For the other densities, a crescent reduction in the number of samples that present lost alleles is shown, as well as the number of lost alleles per sample, extending upwards to the 60 seed-trees/ha density or higher, where the allelic losses do not occur.

The loss of alleles is an aspect of great importance because it is clear evidence of the reduction in the species' genetic basis, which can result in productive losses and especially adaptive losses, compromising the populations' capacity for maintenance. It is worth remembering that the alleles most susceptible to loss are those that present lower frequencies $(p<0.05)$. According to BERGMANN et al. (1990) and MÜLLER-STARCK and SchuberT (2000), rare alleles can be classified as pre-adaptive and they would act like a plug, making the future adaptation of the populations easier when they are submitted to adverse or specific conditions. Looked at this way, the preoccupation about the loss of alleles is primordial, because they are responsible for the possibilities of succeeding in the regeneration of the species and therefore the continuity of management systems. Based on these arguments, the management densities of 5,10 and 20 seed-trees/ha would not be indicated, because they present a high risk of allelic losses, respectively 88.6, 53.5 and $12.5 \%$ (Table 4), which would compromise the objectives of the sustainable management system in what concerns the continuity of the productive process.

\section{Effective population size $\left(N_{e}\right)$}

The value of $N_{e}$ was equal to 543.55 seed-trees not inbred and not relatives, which by the relation $\hat{N}_{e} / n$, confers a genetic representation of $91 \%$. Thus, when the management intensities of 158, 150, 60, 50, 40, 30, 2010 and 5 seed-trees/ha are cited, they actually refer to 144 , 137, 55, 46, 36, 27, 18, 9 and 5 seed-trees/ha not inbred and not relatives, respectively. These estimates is optimistic because heart-of-palm tree phenology presents certain particularities, for example the variation in the number of reproductive individuals per year, the long blossoming period of the species (approximately five months), added to the short duration of male and female blossoming in the inflorescence (from respectively five to seven days and four to six days), which prevent some plants from having an equal opportunity to cross. Besides this, some plants only present male blossoming in certain reproductive events (MANTOVANI and MORELLATO, 2000). Thus, the genetic representation of $91 \%$ is overestimated, because the phenological characteristics of the species promote imbalances in the number of reproductive individuals per year and in the effective contribution of each seed-tree. However, despite the fact that the obtained estimates for the population effective size and genetic representation only consider the population inbreeding, they represent an approximation to the real expected values for this population and suggest the importance of prolonged phenology studies for a more precise estimate of these values.

It is viable to adopt large effective population sizes for the heart-of-palm tree, because the species presents great densities naturally. Therefore, adopting an effective population size of 50 individuals/ha (equal to 55 seed-trees/ha in this paper), which is recommendable for short-term conservation (10 generations) (FRANKEL and SoulÉ, 1981), a managed area of 100 hectares has an total effective population size of 5000 individuals, which is recommendable for long term conservation, i.e., 100 generations (LANDE, 1995). This would guarantee sustainability for managed areas that are greater than, or

Table 4. - Total variation in the loss of alleles, at different management intensities, for a natural population of Euterpe edulis in Ibirama-SC FLONA.

\begin{tabular}{lcccccccc}
\hline Percentage of samples & \multicolumn{10}{c}{ Number of seed-trees/ha } \\
with: & $\mathbf{5}$ & $\mathbf{1 0}$ & $\mathbf{2 0}$ & $\mathbf{3 0}$ & $\mathbf{4 0}$ & $\mathbf{5 0}$ & $\mathbf{6 0}$ & $\mathbf{1 5 0}$ \\
\hline No lost alleles & 11.4 & 46.5 & 87.5 & 98.4 & 99.7 & 99.9 & 100 & 100 \\
1 lost allele & 32.7 & 39.2 & 12 & 1.6 & 0.3 & 0.1 & 0 & 0 \\
2 lost alleles & 32.6 & 13.5 & 0.5 & 0 & 0 & 0 & 0 & 0 \\
3 lost alleles & 19 & 0.8 & 0 & 0 & 0 & 0 & 0 & 0 \\
4 lost alleles & 4.1 & 0 & 0 & 0 & 0 & 0 & 0 & 0 \\
5 lost alleles & 0.2 & 0 & 0 & 0 & 0 & 0 & 0 & 0 \\
Accumulated losses & 88.6 & 53.5 & 12.5 & 1.6 & 0.3 & 0.1 & 0 & 0 \\
\hline
\end{tabular}


equal to, 100/ha for over 100 generations. This way, considering that a heart-of-palm tree generation takes only 20 years (underestimated value), the stocks would be assured for at least 2000 years. However, it is important to remember that densities smaller than 50 seedtrees/ha are not indicated for heart-of-palm tree, because the data that was obtained through cutting simulation shows that the reduction in the heterozygosities, as well as the increase in the fixation index and the alteration in allelic frequencies, would be elevated, compromising the survival of the species populations.

On the other hand, small areas (10 ha) would have a guarantee of middle-term conservation, which could be favored by the gene flow with bigger areas. Based on these considerations, some state forest management regulations (e.g. São Paulo, Rio Grande do Sul and Santa Catarina States) that establish the maintenance of a minimum number of 50 seed-trees/ha in sustainable management plans, guarantee the low risk of genetic diversity losses. However, according to the values that consider the population inbreeding, which were obtained for the effective population size $\left(N_{e}\right)$, it would be recommendable for them to increase the minimum number of seed trees to 55 , which would elevate the effective population size to 50 seed-trees/ha, thereby establishing a safety limit of $10 \%$ in the variation of the inbreeding values, because according to the obtained results, heartof-palm tree populations tend to genetic structure themselves. According to WRIGHT (1931), this increase in the number of individuals would guarantee the conservation of a population for 10 generations (only one managed hectare, where $\hat{N}_{e}=50$ ), and according to LANDE (1995), it would guarantee the conservation of a population for 100 generations (in 100 managed hectares, where $\hat{N}_{e}=5000 / 100$ ha).

Regarding the studies of REIS et al. (2000a), and their proposition about genetic variability distribution and dynamics in natural heart-of-palm tree populations that recommends the maintenance of approximately 60 reproductive individuals per hectare, this is the most indicated for the management of natural populations because it guarantees the maintenance of all studied indexes.

\section{Acknowledgements}

We are grateful to Dr. Alexandre Magno Sebbenn, and anonymous reviewers for critical comments on the manuscript. We also thank to IBAMA (FLONA - Ibirama-SC) for permission to work in their protected area. This work was supported by CNPq.

\section{References}

André, T., M. R. Lemes, J. Grogan and R. Gribel (2008): Post-logging loss of genetic diversity in a mahogany (Swietenia macrophylla King, Meliaceae) population in Brazilian Amazonia. Forest Ecology and Management 255: 340-345.

AlfEnAS, A. C. (1998): Eletroforese de isoenzimas e proteínas afins: fundamentos e aplicações em plantas e microorganismos. Viçosa: UFV.
Bergmann, F., H. R. Gregorious and J. B. LARSEN (1990): Levels of genetic variation in European silver fir (Abies $a l b a)$ - are they related to the species' decline? Genetica 82: $1-10$

Billington, H. L. (1991): Effect of population size on genetic variation in a dioecious conifer. Conservation Biology 5: 115-119.

Conte, R., R. O. Nodari, R. Vencovsky and M. S. Reis (2003): Genetic diversity and recruitment of the tropical palm, Euterpe edulis Mart., in a natural population from the Brazilian Atlantic Forest. Heredity: 91: 401-406.

Conte, R., M. S. Reis, A. Mantovani and R. Vencovsky (2008): Genetic structure and mating system of Euterpe edulis Mart. populations: a comparative analysis using microsatellite and allozyme markers. Heredity: 99(5): 476-482.

FAntini, A. C., R. GuRIEs and R. J. Ribeiro (2000): Produção de palmito (Euterpe edulis Martius - Arecaceae) na Floresta Ombrofila Densa: potencial, problemas e possíveis soluções. Sellowia 49-52: 256-280.

FRANKHAM, R. (1996): Relationship of genetic variation to population size in wildlife. Conservation Biology 10: 1500-1508.

Frankel, O. H. and M. S. SoulÉ (1981): Conservation and evolution. Cambridge: Cambridge University Press.

HAMRICK, J. L. (1991): Allozyme diversity of natural stands versus seed orchard loblolly pine, pp. 1-21. In: Meeting of the Canadian Tree Improvement Association, Proceedings, Ottawa.

Hamrick, J. L., M. J. W. Godt and S. L. Sherman-Broyles (1992): Factors influencing levels of genetic diversity in woody plant species. New Forests 6: 95-124.

KEPHART, S. R. (1990): Starch gel electrophoresis of plant isozymes: a comparative analysis of techniques. Amer. J. Bot. 77: 693-712.

Klein, R. M., U. Pastore and A. B. Coura-Neto (1986): Vegetação, pp. 35-36. In: Atlas de Santa Catarina edited by Gabinete de Planejamento e Coordenação Geral, Florianópolis, SC.

LANDE, R. (1999): Extinction risks from anthropogenic, ecological, and genetic factors, pp. 1-22. In: Genetics and extinction of species, edited by L. A. LANDWEBER and A. P. Dobson, Princeton University Press, Princeton, NJ.

LANDE, R. (1995): Mutation and conservation. Conservation Biology 9: 782-791.

Mantovani, A. and P. Morellato (2000): Fenologia da floração, frutificação, mudança foliar e aspectos da biologia floral. Sellowia 49-52: 23-38.

MÜLler-Stark, G. and R. Schubert (2000): Genetic markers as a tool for bioindication in forest ecosystems, pp. 227-238. In: Forest conservation genetics: principles and practice, edited by A. G. Young, D. Boshier, T. J. Boyle, CSIRO Publishing, Collingwood.

OuborG, N. J. and R. VAN TREuren (1991): The significance of genetic erosion in the process of extinction II. Morphological variation and fitness components in populations of varying size of Salvia pratensis L. and Scabiosa columbaria L. Oecologia 86: 359-367.

Reis, M. S., A. C. Fantini, R. O. Nodari, A. Reis, M. P. GUERRA and A. MANTOVANI (2000a): Management and conservation of natural populations in Atlantic Rain Forest: the case study of Palm Heart (Euterpe edulis Martius). Biotropica, 32: 894-902. 
Reis, M. S., R. Conte, R. O. Nodari, A. C. FAntini, A. Reis, A. Mantovani and A. Mariot (2000b): Manejo sustentável do palmiteiro. Sellowia 49-52: 202-224.

Reis, M. S., M. P. GuerRA and R. O. NodARI (1998): Management of natural populations and maintenance of genetic diversity, pp. 145-156. In: Recent advances in biotechnology for tree conservation and management. IFS Proceedings, Stockolm.

Sebbenn, A. M., C. E. S. Seoane, P. Y. Kageyama and R. Vencovsky (2000): Efeitos do manejo na estrutura genética de populações de caixeta (Tabebuia cassinoides). Scientia Forestalis 58: 127-143.

Swofford, D. L. and R. B. Selander (1989): Biosys-1: A computer program for the analysis of allelic variation in population genetics and biochemical systematics. Natural History Survey, Illinois.
VENCOVsKY, R. (1997): Biometrical approaches for molecular markers: estimation of effective population size, $2 p$. In: International Workshop on Agricultural Biotechnology, Proceedings ESALQ-USP, Piracicaba, Cook College - New Jersey Agricultural Experiment Station, The State University of New Jersey.

Vergeer, P., R. Rengelink, A. Copal and J. Ouborg (2003): The interacting effects of genetic variation, habitat quality and population size on performance of Succisa pratensis. Journal of Ecology 91: 18-26.

White, G. M., D. H. Boshier and W. Powell (1999): Genetic variation within a fragmented population of Swietenia humilis Zucc. Molecular Ecology 8: 1899-1909.

Wright, S. (1931): Evolution in Mendelian populations. Genetics 16: 97-159.

\title{
Performance of Acacia senegal (L.) Willd Provenances in Dryland Savannah of Niger
}

\author{
By M. LARWANou ${ }^{\left.1,{ }^{*}\right)}$, A. RAEBILD ${ }^{2,3)}$, R. Issa ${ }^{1)}$ and E. D. KJÆR ${ }^{2)}$
}

(Received 24 ${ }^{\text {th }}$ March 2009)

\begin{abstract}
A study was conducted to evaluate the performance of 11 Acacia senegal provenances in Niger, West Africa, grown on 2 different soil types. Among the provenances, 6 are from Niger, 4 from Mali and 1 from Sudan. The assessment was carried out with measurements of growth parameters (survival rate, height, diameter and basal area) as well as gum and fruit production at age 15.

The results showed significant differences in growth parameters between soil types and provenances. The provenances from Mali perform best, followed by the local Niger provenances. There were no significant dif-

\footnotetext{
1) Université Abdou Moumouni, Faculté d'Agronomie, Niamey, Niger.

2) University of Copenhagen, Centre for Forest, Landscape and Planning, Hørsholm Kongevej 11, DK-2970 Hørsholm, Denmark.

${ }^{3}$ ) Corresponding author: Phone +45 35331619, Fax +45 35331517. E-Mail: are@life.ku.dk

*) Present address: African Forest Forum, c/o World Agroforestry Center (ICRAF), United Nations Avenue, P.O. Box 3067700100, Nairobi, Kenya.
}

ferences in gum and fruit production between provenances, but it cannot be excluded that this was a result of limited power in the test of provenance variation in these traits. Survival of the provenances was correlated to the precipitation and the latitude of the origin, whereas basal area was correlated to latitude, and height was correlated to longitude/altitude at the origin.

Recommendations could be made for genetic selection of two Mali provenances if growth is a desired character. We conclude that recommendations in terms of gum and fruit production must be based on a relative high number of sample trees as tree to tree variation within provenances may be large.

Key words: Acacia senegal, gum arabic, growth, Niger, Provenance trial, clines.

\section{Introduction}

In many African countries, Acacia senegal (L.) Willd. (Mimosaceae) plays an important role in poverty reduction. In dryland Africa, the species is used by rural people for ecological, economic, social and even cultural purposes. A. senegal is known as gum Arabic, and the tree produces gum which is used for food, medicine and in ceremonies. The gum is sold and procures revenues that 